\title{
Non-suicidal self-injury and emotion regulation: a review on facial emotion recognition and facial mimicry
}

\author{
Tina In-Albon ${ }^{*}$, Martina Bürli², Claudia Ruf ${ }^{2}$ and Marc Schmid ${ }^{3}$
}

\begin{abstract}
Non-suicidal self-injury (NSSI) is an increasingly prevalent, clinically significant behavior in adolescents and can be associated with serious consequences for the afflicted person. Emotion regulation is considered its most frequent function. Because the symptoms of NSSI are common and cause impairment, it will be included in Section 3 disorders as a new disorder in the revised Diagnostic and Statistical Manual of Mental Disorders (DSM-5). So far, research has been conducted mostly with patients with borderline personality disorder (BPD) showing self-injurious behavior. Therefore, for this review the current state of research regarding emotion regulation, NSSI, and BPD in adolescents is presented. In particular, the authors focus on studies on facial emotion recognition and facial mimicry, as social interaction difficulties might be a result of not recognizing emotions in facial expressions and inadequate facial mimicry. Although clinical trials investigating the efficacy of psychological treatments for NSSI among adolescents are lacking, especially those targeting the capacity to cope with emotions, clinical implications of the improvement in implicit and explicit emotion regulation in the treatment of NSSI is discussed. Given the impact of emotion regulation skills on the effectiveness of psychotherapy, neurobiological and psychophysiological outcome variables should be included in clinical trials.
\end{abstract}

Keywords: Non-suicidal self-injury, Emotion regulation, Facial emotion recognition, Facial mimicry, Borderline personality disorder

\section{Introduction}

Non-suicidal self-injury (NSSI) is defined as the direct, repetitive, intentional injury of one's own body tissue, without suicidal intent, that is not socially accepted [1]. The latest studies exploring the occurrence of NSSI in community samples of 14- to 23-year-olds have found its prevalence to range between 10.9 and $38 \%$ ([2-5]; see [6] for an overview). However, a one-time occurrence should not be considered pathological. In the diagnostic criteria for NSSI for the fifth edition of the Diagnostic and Statistical Manual of Mental Disorders (DSM-5) of the American Psychiatric Association [7,8], NSSI needs to occur at least five times to be regarded as problematic. This repetitive NSSI (more than four times) is found in 4$6 \%$ of adolescents ([2,5,9]; see [10] for an overview). In a

\footnotetext{
* Correspondence: in-albon@uni-landau.de

${ }^{1}$ Clinical Child and Adolescent Psychology, Department of Psychology, Universität Koblenz-Landau, Ostbahnstrasse 10, Landau D-76829, Germany Full list of author information is available at the end of the article
}

child and adolescent psychiatric inpatient setting, over $25 \%$ of adolescents were found to engage in this behavior [2]. Common forms include cutting, severe scratching, burning, and banging or hitting, especially on the arms, legs, stomach, head, and genitals [11]. Rates of NSSI in females and males differ to a much lesser degree than previously assumed $[4,12]$, but females engage in more frequent NSSI than males [13]. The frequency and degree of injuries influence the prognosis of psychotherapeutic treatment [14]. Repetitive NSSI is associated with various concerns, among them depressive symptoms, self-esteem problems, alcohol and drug abuse, interaction problems with peers and family members, poor academic performance, and behavior problems [11,15]. NSSI in adolescence is also a risk factor for NSSI in adulthood and death by suicide [16].

Affective, externalizing, anxiety, substance abuse, and borderline personality disorders are common comorbid diagnoses with NSSI [17]. NSSI most often begins

\section{Biomed Central}


between the ages of 12 and 15 [18] and can last for weeks, months, or even years. It would be erroneous, however, to assume that NSSI is a fleeting adolescent phenomenon. Although the majority of college students surveyed reported stopping within 5 years of starting, it is also clear that the behavior can last well into adulthood [13]. Furthermore, early onset of NSSI is associated with unfavorable treatment outcome in adults [14]. Even though NSSI is a serious condition, only a minority of adolescents receives professional help $[2,19]$.

Because of the frequent occurrence of this serious behavior, the definition of NSSI has become more stringent, and several researchers have proposed that the disorder should be included as a new entity in the revised classification system (DSM-5) [7,8], suggesting that NSSI is a common, impairing, and distinctive disorder and therefore should be included in the DSM to decrease misperceptions that arise because of a lack of clarity about NSSI's definition and significance. The list below provides the proposed DSM-5 criteria for NSSI. NSSI will be included in Section 3 disorders of the DSM-5 [20], indicating that the criteria set need further research before it will be an official diagnosis. Results of $D S M-5$ field trials also suggest further research as two sites had inadequate sample sizes for a successful field trial and for one field trial the estimate of the intraclass kappa was in the unacceptable range [21].

\section{Diagnostic criteria for non-suicidal self-injury (NSSI) proposed for the fifth edition of the Diagnostic and Statistical Manual of mental disorders ${ }^{a}$}

A.In the last year, the individual has, on 5 or more days, engaged in intentional self-inflicted damage to the surface of his or her body, of a sort likely to induce bleeding or bruising or pain (e.g., cutting, burning, stabbing, hitting, excessive rubbing), for purposes not socially sanctioned (e.g., body piercing, tattooing, etc.), but performed with the expectation that the injury will lead to only minor or moderate physical harm. The behavior is not a common one, such as picking at a scab or nail biting.

B. The intentional injury is associated with at least 2 of the following:

1. Psychological Precipitant: Interpersonal difficulties or negative feelings or thoughts, such as depression, anxiety, tension, anger, generalized distress, or self-criticism, occurring in the period immediately prior to the self-injurious act.

2. Urge: Prior to engaging in the act, a period of preoccupation with the intended behavior that is difficult to resist.
3. Preoccupation: Thinking about self injury occurs frequently, even when it is not acted upon.

4. Contingent Response: The activity is engaged in with the expectation that it will relieve an interpersonal difficulty, or negative feeling or cognitive state, or that it will induce a positive feeling state, during the act or shortly afterwards.

C. The behavior or its consequences cause clinically significant distress or interference in interpersonal, academic, or other important areas of functioning. (This criterion is subject to final approval on the use of criteria that relate symptoms to impairment).

D. The behavior does not occur exclusively during states of psychosis, delirium, or intoxication. In individuals with a developmental disorder, the behavior is not part of a pattern of repetitive stereotypies. The behavior cannot be accounted for by another mental or medical disorder (i.e., psychotic disorder, pervasive developmental disorder, mental retardation, Lesch-Nyhan Syndrome, stereotyped movement disorder with self-injury, or trichotillomania).

E. The absence of suicidal intent has either been stated by the patient or can be inferred by repeated engagement in a behavior that the individual knows, or has learnt, is not likely to result in death.

${ }^{\mathrm{a}}$ As of November 2012, www.dsm5.org.

NSSI is, like suicidal behavior, one of the nine symptoms of borderline personality disorder (BPD) in the DSM-IV-TR [22]. BPD is characterized in adolescents and adults by problems with emotion regulation, interpersonal relationships, self-image, affectivity, and impulsivity. However, although NSSI and BPD often co-occur, they also occur independently. It should not be concluded that all adolescents with NSSI fulfill diagnostic criteria for BPD. Even early reports warned against subsuming NSSI under a specific personality disorder. In fact, only about $50 \%$ of those who engage in NSSI suffer from BPD [23-25]. Another important distinction has to be made between NSSI and attempted suicide, as the behaviors are indeed different. Three key differences are noteworthy: First, most people engaging in NSSI have no intent to die while conducting the self-injurious act; nevertheless, many people suffering from NSSI report suicide ideas and plans. Second, NSSI is less severe than attempted suicide and usually the damage is not life threatening. Third, NSSI and attempted suicide differ in the frequency of the act, as NSSI often occurs daily [26,27]. In line with several authors (e.g., [28-31]), we propose that NSSI can be regarded as a response for managing or inhibiting aversive emotions, thus representing a dysfunctional emotion regulation strategy. 
In the remainder of this consolidated review we provide an overview of emotion regulation and its importance in social relationships. We then focus on two aspects of emotion regulation in adolescents: facial emotion recognition and facial mimicry (the tendency for people to imitate or mimic the facial expressions of others). As mentioned above, interaction problems are often a trigger for NSSI, so the question of what contributes to these social problems should be addressed. Therefore, after we review the empirical studies conducted to date, we attempt to derive suggestions for future theoretical and clinical research.

We have included only published studies with no other limitations. The literature search for this review was conducted in PubMed and PsycINFO using the following keywords: adolescents, non-suicidal self-injury, self-injury, self-harm (but it had to be clear that the selfinjury or self-harm was performed without suicidal intent or was not a socially accepted behavior), borderline personality disorder, facial mimicry, and facial recognition. Study selection was independent of date of publication or type of document (review or original research).

\section{Emotion regulation}

Emotion dysregulation plays a central role in the development and maintenance of mental disorders [32]. Indeed, the majority of disorders in the DSM-IV-TR include at least one symptom reflecting a disturbance in emotion regulation [33]. Empirically supported theories of how emotion dysregulation manifests in, maintains, and contributes to mental disorders are increasing, which in turn has stimulated evidence-based treatment development [34]. Figure 1 shows an affect regulation model developed by Herpertz ([35], see also [36]) that describes implicit and explicit affect regulation mechanisms, which can be influenced through arousal, emotional sensibility, and more-or-less helpful and adaptive regulation strategies. Problems in implicit emotion regulation might result from classical conditioning of emotionally stressful experiences to stimuli associated with stressful or traumatic situations. Maladaptive and adaptive explicit emotion regulation strategies might be a result of a person's social learning history [36].

Increasing attention has been paid to emotion regulation as a potentially unifying function of maladaptive behaviors [37]. The most comprehensive work highlighting emotion dysregulation in psychopathology is Linehan's [38] biosocial theory on the development of BPD. Her theory has been verified by an increasing number of psychophysiological, genetic, and neuroimaging studies on the development of severe emotion regulation problems, especially in patients suffering from BPD $[39,40]$. According to this theory, emotion dysregulation is one of the central features of BPD and underlies many associated behaviors of this disorder, including NSSI. This construct of emotion (and thus of emotion dysregulation) is very broad and includes emotion-linked cognitive processes, facial and muscle reactions, action urges, physiology, and emotionlinked actions [39]. Symptoms such as impulsive and NSSI are either the direct or the indirect consequence of emotion dysregulation or attempts to modulate intense emotional reactions [38]. Emotion dysregulation in BPD is hypothesized to consist of greater emotional sensitivity (low threshold for recognition of or response to emotional stimuli) (e.g., [40]), greater emotional reactivity (increased amygdala activity) [41,42], and a slower return to baseline arousal ([43]; for an overview see [44]). Linehan's conceptualization of NSSI as an emotion regulation strategy is supported by both empirical and theoretical literature on the function of this behavior $[45,46]$. Many patients with NSSI have major problems with emotion regulation due to biological disposition and an emotionally invalidating environment [38]. An emotionally invalidating environment is one in which a person's emotional experiences are not responded to in an appropriate or consistent manner. Such an environment does not allow individuals to learn how to regulate intense emotions in an adaptive way and to trust their own experiences as valid and real. Thus, these individuals rely on short-term, impulsive strategies to restore emotions to a tolerable level.

\section{Emotion regulation in normal development and in adolescence}

Developing skill in emotion regulation involves many factors, including self-awareness of emotion, an appreciation of the origins of emotional experience, an understanding of the potential consequences of emotional expression in different circumstances, and strategies for modifying emotion [47]. The development of emotion regulation begins in early childhood (e.g., sucking a thumb, social referencing) and continues throughout life. In adolescence the understanding of how emotion functions and is managed within oneself becomes evident and provides an important contribution to the emergence of self-understanding [48].

Adolescence is a transition period from childhood to adulthood that is often characterized by instability in body image, identity, and emotion [49]. Key developmental issues in adolescence include autonomy and self-definition, separation from parents, and emotion regulation in physiological and relational maturation. Therefore, adolescence can be considered a period of heightened stress and increased incidence of psychopathology [50]. It is not surprising, then, that pathological personality traits are much more frequent in adolescence than in adulthood [51,52]. Recent neurobiological studies have indicated that structural brain development continues until young adulthood, and neurobiological changes may also impact emotion regulation abilities (see [53-55]). With regard to emotion 


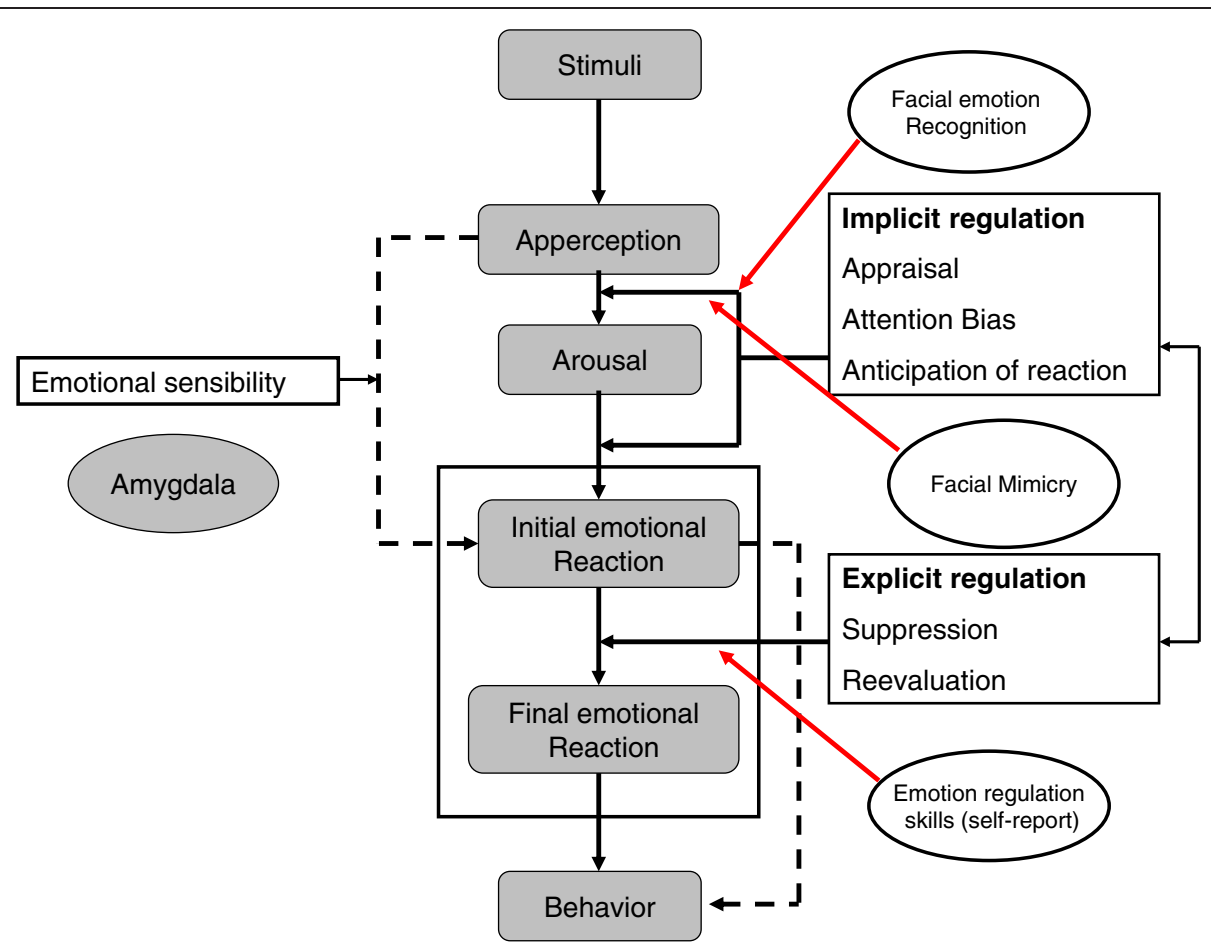

Figure 1 Herpertz's affect regulation model [26], including the components facial emotion recognition, facial mimicry, and emotion regulation skills.

regulation, there is a change during adolescence in grey and white matter in the cortex [56-58], which could help explain difficulties in cognitive control and emotion regulation during adolescence. Other neurobiological explanations for emotion dysregulation during adolescence are substantial changes in the neurotransmission of dopamine (e.g., [59]) and changes in endocrinology and hormonal status (e.g., [60]). Neurobiological development during adolescence and its influence on the capacity to regulate emotions might be a factor in the peaking of NSSI during adolescence [61].

\section{Emotion regulation in the development and maintenance of psychopathology and NSSI}

Behavioral theories of psychopathology highlight the importance of the functions that problematic behaviors serve [62]. Emotion regulation is considered the most frequent function of NSSI and is associated with decreases in affective arousal and improvements in affective valence [63-65]. In fact, it is likely that NSSI serves multiple functions simultaneously [66]. The increasing recognition of emotion regulation deficits in NSSI is addressed in the suggested DSM-5 criteria for NSSI disorder: Criteria B includes emotion regulation deficits-for example, negative feelings or thoughts, such as depression, anxiety, tension, anger, generalized distress, or self-criticism-occurring in the period immediately prior to the self-injurious act; the activity is engaged in with a purpose; this might be relief from a negative feeling/cognitive state or interpersonal difficulty or induction of a positive feeling/state [7]. Emotions such as anger, anxiety, and frustration tend to precede NSSI, which is often followed by feelings of relief and calm in the short term but leads to sadness, guilt, anxiety, disgust, and anger in the long term $[65,67,68]$. In a physiological study [29], emotional responses to personalized scripts of self-harm incidents in male prisoners with a history of self-injury were examined. Compared to controls, self-harming participants responded with a decrease in physiological arousal and self-reported negative emotion to self-harm imagery but not to the imagery of an accidental injury or a neutral situation. In a second study [69], the tension-reducing effect of self-harming was replicated. Evidence for heightened emotional reactivity and low distress tolerance in adolescents with NSSI was found [70]. In this study adolescents with a history of NSSI reacted with increased skin conductance response to a stressinducing task and decreased willingness to tolerate this distress and decreased persistence at the task. Several other studies indicated that patients who engage in NSSI are not able to perceive their feelings at all, or sometimes the opposite: that is, they perceive them much too strongly and aversively (e.g., [43,70]). Adolescents with NSSI suffer from intense negative emotions associated with high arousal. Both seem to increase rapidly and can be reduced only by NSSI or other extreme stimuli [70,71]. 
In addition, adolescents with NSSI have no other way to deal with emotions in social interactions [71].

\section{Models of NSSI}

To date, there are two theoretical models of NSSI that include an emotion regulation component [72,73]. One is an integrated theoretical model of the development and maintenance of NSSI [73]. The model contains three major propositions. First, NSSI is maintained because it is an effective means of immediately regulating aversive affective/cognitive experiences and/or social situations. Second, the risk of NSSI is increased by distal factors that can lead to interpersonal (e.g., poor communication skills, poor social problem solving) and intrapersonal (e.g., poor distress tolerance, high aversive emotions) vulnerabilities that predispose people to respond to stressful events with affective or social dysregulation, creating a need to use NSSI or other extreme behavior to modulate their experience. Third, the risk of engaging in NSSI is increased by several self-injury-specific factors.
The second, experiential avoidance model [72] is an evidence-based theoretical framework highlighting maintenance of NSSI by negative reinforcement of unwanted emotional expressions. Figure 2 shows a "vicious circle," indicating how difficulties in social interactions may lead to misperceptions and consequently an increase in emotional arousal and a worsening of mood state. This circle highlights one aspect of emotion dysregulation in more detail, whereas the theoretical models [72,73] describe the development and maintenance in a broader way. Our circle concept is meant to be used as a guideline in treatment and psychoeducation. The main aspect of the circle model is that it shows it is necessary to be mindful of the first slight recognitions of emotions and to sensitize patients to their own emotions. The model can help patients understand two things. The initial recognition of emotions is important in choosing adequate behavior strategies and reducing the development of stress and tension. Recognizing an increasing stress level is important for developing skills in stress reduction to prevent self-injury and repeating the




experience of the inability to cope with displeasing emotions (see Clinical Implications).

\section{Emotion regulation and social relationships}

The manner in which people regulate emotions affects their relationships, and vice versa. In social interactions, emotional suppression seems to decrease both negative and positive emotion-expressive behavior, thereby masking important social signals that would otherwise be available to social interaction partners [74]. In addition, the ongoing monitoring of an individual's own facial expression could distract the suppressing individual and make that person less responsive to the emotional cues of an interaction partner. Studies investigating this theory found that partners of suppressing participants showed greater increases in blood pressure than partners of participants who were either reappraising or acting naturally. These findings indicate that interacting with a partner who shows little positive emotion and who is unresponsive to emotional cues is more physiologically activating than interacting with a partner who shows greater positive emotion and responsiveness [75]. Furthermore individuals who suppressed emotions were less likely to share both their negative and positive emotions with others, had poorer social support, and were less likely to be liked [76]. Recent studies indicate that culture can be a moderator of the effect of emotion suppression on social interactions [77]; further research is needed.

Emotion regulation influences emotional expression and behavior directly. In contrast, the ability to perceive and understand emotions indirectly influences social interaction by helping people interpret internal and social cues, thereby guiding emotional self-regulation and social behavior. Deficits in emotional expression appear to be a risk factor for internalizing and externalizing psychopathology [78]. Emotion perception is an important prerequisite for emotion regulation [79]. If emotional facial expressions are not recognized correctly, emotion regulation will be influenced. Emotion regulation can influence social interaction through several mechanisms. Most saliently, it colors the emotional tone of social encounters. Displays of pleasant emotions tend to elicit favorable responses from others, whereas the expression of negative emotions causes heterogeneous reactions in other people. Most people try to console others who are experiencing negative emotions and offer help and personal support to people who are feeling grief or fear, especially if they are in an emotional relationship with them and doing so might enhance intimacy. This social reinforcement of expressions of negative emotions and moods might have some influence on the development of mental disorders. Some people, however, feel uncomfortable if they are confronted with expressions of negative emotions and drive them away [80].
Chronic difficulties in interpersonal relationships are a core dimension of BPD. BPD patients were found to have fewer social contacts compared to patients with other personality disorders or healthy control groups, and they characterized their social interactions as more disagreeable, ambivalent, angry, empty, and sad [81]. Social situations have been found to be potent triggers for emotional arousal and affective instability in BPD [82]. Interpersonal situations are of high relevance for patients with NSSI. In a German study, adolescents with NSSI $(n=220)$, compared to healthy controls $(n=4,693)$, reported significantly more problems, such as relationship problems within the family and with peers [15]. Interpersonal stress was also associated with engaging in NSSI [83], and quality of peer communication moderated this relationship. Furthermore, adolescents with NSSI often reported engaging in NSSI to influence behaviors of others [83]. It is important to note that a social perspective is compatible with, and meant to supplement, the aforementioned emotion regulation perspective. Patients with NSSI are often not able to tolerate emotional distress and can only regulate subjectively overwhelming and uncontrollable emotions with NSSI. In the modified model (Figure 1), facial emotion recognition and facial emotion expressivity are highly important prerequisites for adequate emotion regulation. In the following, studies investigating facial emotion recognition and facial mimicry are presented in further detail.

\section{Facial emotion recognition}

Facial emotion recognition is impaired in several disorders, such as autism, schizophrenia, depression, anxiety disorders, antisocial personality disorder, and psychopathy. Recognition of facial affect has been investigated mostly using pictures of static or dynamic facial expressions of emotions that have to be attributed to an emotion (see [40] for a review). According to the biosocial theory [38], emotion dysregulation in adult BPD, which is also often characterized by NSSI, is hypothesized to be a consequence of greater emotional sensitivity. In adolescents with NSSI, no studies on facial emotion recognition exist. There are two studies that addressed facial emotion recognition in a sample with adolescents and young adults with symptoms of BPD $[84,85]$. In the study of Jovev et al. [84], 21 outpatient adolescents meeting three or more DSM-IV criteria of BPD and 20 healthy controls participated. They viewed 30 pictures of dynamic facial expressions changing slowly from a neutral face to a prototypical expression of sadness, disgust, surprise, fear, anger, or happiness in 25 steps. The task was to press the space bar as soon as the emotion had been recognized. Image number at the time of response was recorded as an indicator of detection threshold. Recognition accuracy was measured using a 
forced-choice format, where one of the abovementioned emotions had to be chosen. Results revealed no heightened sensitivity to emotional expressions in youth with BPD symptoms as compared to healthy controls. Youth with BPD symptoms correctly identified emotional facial expressions at the same threshold of expressivity as healthy controls. The authors suggested that heightened sensitivity to emotional expression might only be apparent in severe BPD or might develop later in the course of the disorder. The second study, investigating facial emotion recognition in female adolescents with BPD, demonstrated that happy facial expressions were perceived as less friendly, and patients perceived them as more threatening than healthy controls did [85]. However, there were no deficits in naming the displayed emotions, nor differences regarding the subjective ratings of the negative and neutral facial expressions.

In summary, the two studies conducted so far indicated that adolescents with symptoms of BPD display a normal ability to recognize facial emotions. The studies used different methods and designs, and certain limitations have to be mentioned. For example, both studies used black-and-white pictures $[84,85]$. One used a questionnaire to investigate the perception of emotional facial expressions, and static facial expressions [85]. The other had no clinical control group [84]. Due to the low number of studies, results have to be replicated. In addition, the emotional state of the participants should be controlled, for instance, with mood induction.

\section{Facial mimicry}

As is emotion perception and identification, the expression of emotions is important for social interactions. Because humans are a social species, social coordination is essential for survival [86]. Darwin [87] argued that facial expressions of emotion have an adaptive value in social communication because they reveal something about the inner state of the responder that is observable to others. Emotions are highly contagious [80]. An important aspect of emotional contagion, facial mimicry encourages relationships and empathy and therefore represents an important social catalyst [88]. Mirroring emotional facial expressions is a robust effect in healthy persons as they spontaneously and quickly activates congruent facial muscles [89]. Facial mimicry is observable in infants as young as $12-21$ days old and plays an important role in establishing attachment through mother-child interactions [90].

Interpersonal situations are highly rule governed and these rules are perceived as normative for interactions [91]. Even minor violations of rules guiding emotional behavior can create substantial problems for the interaction process [86]. Thus, difficulties in social interaction and resulting problems of, for example, social rejection might be understood as violations of social rules due to nonconformity in facial mimicry.

One method used to measure subtle changes in facial muscle activity is electromyography (EMG). EMG analyses are automatic, are more sensitive to subtle muscle activity, and provide exact temporal and quantitative information about the emotional reaction after stimulus presentation [92]. Most research on facial mimicry in children has been conducted in children with autism spectrum disorder (e.g., [93,94]); none has yet been conducted with adolescents with NSSI or BPD. Because of the comorbidity of NSSI and affective disorders [23], we present one study with dysphoric students. The results of this study indicated that in contrast to healthy controls, dysphoric students did not show an increase in $m$. zygomaticus EMG activity in response to happy facial expressions but rather displayed an increase in $m$. corrugator EMG activity [95].

Given the relationship problems of adolescents with NSSI, it might be interesting to explore whether adolescents with NSSI have deficits in facial mimicry, which could lead to problems in social interactions, which trigger NSSI-a vicious circle, perpetuating the problem. Studies investigating these aspects of emotion regulation will provide a better understanding of NSSI and emotion dysregulation. Results will also have theoretical and practical implications for mental health care of adolescents with NSSI.

\section{Implications}

Current research in clinical psychology has increasingly recognized the importance of the assumption that deficits in emotion regulation skills contribute to the development and maintenance of psychopathology (e.g., [96]).

\section{Clinical implications}

Clinical implications of these studies can be derived from the above-mentioned tasks of emotion regulation. Daily social interactions require a differentiated perception of emotions for adequate contact with fellow human beings. If emotions cannot be identified correctly or are identified relatively late, then this may lead to an increase of emotional arousal and a worsening of mood state, which in a vicious circle may lead to more misperception and finally to strong negative emotions (see Figure 2).

According to Marsha Linehan's biosocial theory [38] people suffering from NSSI might have problems with emotion regulation because of a biological predisposition in combination with a social learning history of emotional invalidation in their families. These experiences may make them feel uncomfortable with emotions and may lead to a tendency to negate emotions. As a result of this negation of emotions they cannot react adequately to their 
emotions at a low level of tension. With increasing stress and tension it gets harder and harder to choose appropriate behavior strategies and to solve interactional problems, which could lead to acts of NSSI [44,97].

Affected adolescents may have an increased risk of NSSI, which may be an inadequate attempt to regulate their emotions given the problems they have recognizing their own emotions and interacting with partners' feelings. If adolescents with NSSI have difficulties in facial emotion recognition and expressions, future treatment and prevention of NSSI would likely benefit from training modules to practice recognizing initial facial expressions in interpersonal situations. Working with video and computer animations may be helpful to support this training process. Because every emotion has a typical physical expression, biofeedback procedures can improve sensitivity to patients' own emotions. Patients should learn to react immediately to discrete precursors of emotions and should develop the social skills needed to express their emotions adequately and resolve the triggering situation [97]. According to the BPD theory of emotion regulation that is applied to NSSI in adolescents, strong emotion and arousal create the behavioral act of self-injury to modulate negative affects. Therefore, social skills are needed to help prevent and better express heightened emotion. This is important, as evidence on the effectiveness of specific treatments for adolescents with NSSI is lacking. This lack of evidencebased treatments makes treating adolescents with NSSI difficult and often quite scary for clinicians [98,99]. This might explain the high rate of untreated adolescents suffering from NSSI and the high drop-out rates in outand inpatient psychotherapy $[9,92]$.

Currently, psychotherapies that emphasize emotion regulation, functional assessment, and problem solving appear to be the most effective for treating NSSI [100]. In addition, dialectic behavior therapy (DBT), which is showing preliminary efficacy in adolescents with BPD [99], may be one of the most promising treatments for adolescents with NSSI [98,101]. Linehan et al. [44] suggested it is important in behavior analysis to acknowledge the difference between a high intensity of displayed emotions and a high level of an inappropriate emotion. In the first case, the best intervention will be problem solving, role playing, and the improvement of selfefficacy to cope with difficult interactions. In the second case, it will be necessary for the patient to have the opportunity to reevaluate the emotionally stressful situation and to realize that intense emotion was not necessary and helpful in this situation. To allow reevaluation, an exposure to the emotionally stressful situation will be the best psychotherapeutic intervention. Experiencing that the emotion and interpretations were inadequate in the situation promotes alternative behavior.
To show the effectiveness of skills training to improve implicit and explicit emotion regulation capacities, it might be useful to assess the subjective improvement of patients with evaluated questionnaires. Recent studies indicate that adding psychophysiological and neurobiological measurements may be useful $[102,103]$, nevertheless future research has to show accuracy and feasibility. Successful skills training has been shown to change amygdala activity in response to fearful and disgusting pictures [104]. Other studies have shown different changes in the hypothalamic-pituitary-adrenal axis activity [105].

DBT is a behavioral treatment that draws its principles from behavioral science, dialectic philosophy, and Zen practice. The treatment focuses on factors that maintain dysfunctional behaviors, such as reinforcers of NSSI. Furthermore, DBT emphasizes the balance of acceptance and change [38]. The concept of emotion dysregulation could also be an important topic to address in the psychoeducation of affected family members. Especially for adolescents, it seems very important to do sufficient work with parents, because all family members show a high emotional burden and need help understanding the adolescent and interacting in a way that promotes emotional validation $[106,107]$. In summary, research in the field of NSSI has increased (especially in relation to BPD), but the number of studies with adolescents still lags far behind the number with adults, despite the prominence of NSSI during this development phase.

\section{Theoretical implications}

An important methodological aspect of facial affect recognition research is the type of stimuli used. Dynamic facial expressions are more realistic than those that are static and result in stronger activity in the amygdala, a brain area involved in the processing of emotional information $[108,109]$. Thus, future research on emotion recognition in NSSI should use dynamic facial expressions of emotions. In addition, color pictures of facial expressions might be more realistic than black-and-white images. It will be important to employ a clinical comparison group to ensure the specificity of the results. NSSI is often accompanied by comorbidities $[17,23]$ that are associated with deficits in emotion recognition [40]. Therefore, facial emotion recognition studies in patients with NSSI might profit from large study samples that include comparison groups of individuals with comorbid major depression, anxiety disorders, BPD, and/or other disorders.

Although facial mimicry is a stable effect, studies investigating adolescents with NSSI and BPD should include it as a component, as deficits in facial mimicry can result in social interaction difficulties and misunderstandings and then function as a trigger for NSSI. Studies investigating facial mimicry-such as 
those on facial recognition-should use dynamic facial expressions because they evoke stronger facial mimicry compared to static expressions [110,111]. Future research directions with clinical implications include intervention studies that examine whether improvement in emotion recognition mediates therapeutic reductions in NSSI and studies of the relation between NSSI and emotion regulation capacity in youths. Results will have theoretical and clinical implications and promote our understanding of the many adolescents suffering from NSSI.

The ethics committee approved the study.

\section{Competing interest}

The authors declare that we have nonfinancial competing interests.

\section{Authors' contributions}

TI made substantial contributions to the ideas of the paper, the drafting and the revision of the manuscript. MB and CR contributed to the drafting and the revision of the manuscript. MS contributed to the ideas, the drafting and the revision of the manuscript. All authors read and approved the final manuscript.

\section{Acknowledgments}

The preparation of this manuscript was supported by grant project 100014_135205 awarded to Tina In-Albon in collaboration with Marc Schmid by the Swiss National Science Foundation.

\section{Author details}

'Clinical Child and Adolescent Psychology, Department of Psychology, Universität Koblenz-Landau, Ostbahnstrasse 10, Landau D-76829, Germany. 2Division of Clinical Psychology and Psychotherapy, University of Basel, Department of Psychology, Basel, Switzerland. ${ }^{3}$ Department of Child and Adolescent Psychiatry, University of Basel, Basel, Switzerland.

Received: 31 October 2012 Accepted: 14 February 2013 Published: 20 February 2013

\section{References}

1. Lloyd-Richardson EE, Perrine N, Dierker L, Kelley ML: Characteristics and functions of non-suicidal self-injury in a community sample of adolescents. Psychol Med 2007, 37:1183-1192.

2. Brunner R, Parzer P, Haffner J, Steen R, Roos J, Klett M, Resch F: Prevalence and psychological correlates of occasional and repetitive deliberate selfharm in adolescents. Arch Pediatr Adolesc Med 2007, 161:641-649.

3. Gratz KL, Conrad SD, Roemer L: Risk factors for deliberate self-harm among college students. Am J Orthopsychiatry 2002, 72:128-140.

4. Muehlenkamp JJ, Gutierrez PM: An investigation of differences between self-injurious behavior and suicide attempts in a sample of adolescents. Suicide Life Threat Behav 2004, 34:12-23.

5. Plener PL, Libal G, Fegert JM, Muehlenkamp JJ: An international comparison of adolescent non-suicidal self-injury (NSSI) and suicide attempts: Germany and USA. Psychol Med 2009, 39:1549-1558.

6. Plener PL, Brunner R, Resch F, Fegert JM, Libal G: Nonsuicidal self-injury in adolescence. Z Kinder Jugendpsychiatr Psychother 2010, 38:77-88.

7. Shaffer D, Jacobson C: Proposal to the DSM-V childhood disorder and mood disorder work groups to include non-suicidal self-injury (NSSI) as a DSM-V disorder. www.dsm5.org.

8. Plener P, Fegert JM: Non-suicidal self-injury: state of the art perspective of a proposed new syndrome for DSM-V. Child Adolesc Psychiatry Ment Health 2012, 6:9.

9. Rauber R, Hefti S, In-Albon T, Schmid M: Wie psychisch belastet fühlen sich selbstverletzende Jugendliche? Kindheit Entwicklung 2012, 21:23-39.

10. Muehlenkamp JJ, Claes L, Havertape L, Plener PL: International prevalence of adolescents non-suicidal self-injury and deliberate self-harm. Child Adolesc Psychiatry Ment Health 2012, 30:6.

11. Brunner R, Resch F: Zur Abgrenzung der Borderlinepersönlichkeitsstörung von schweren Adoleszenzkrisen im Jugendalter. In Borderline-Störungen und Selbstverletzendes Verhalten im Jugendalter. Edited by Brunner R, Resch F. Göttingen: Vandenhoeck \& Ruprecht; 2008:134-148.

12. Klonsky MA, Oltmanns TF, Turkheimer E: Deliberate self-harm in a nonclinical population: prevalence and psychological correlates. Am J Psychiatry 2003, 160:1501-1508.

13. Whitlock JL, Eckenrode JE, Silverman D: Self-injurious behavior in a college population. Pediatrics 2006, 117:1939-1948.

14. Zanarini MC, Frankenburg FR, Reich DB, Fitzmaurice G, Weinberg I, Gunderson JG: The 10-year course of physically self-destructive acts reported by borderline patients and axis II comparison subjects. Acta Psychiatr Scand 2008, 117:177-184.

15. Vonderlin E, Haffner J, Behrend B, Brunner R, Parzer P, Resch F: Welche Probleme berichten Jugendliche mit selbstverletzendem Verhalten? Ergebnisse einer repräsentativen Schülerbefragung. Kindheit Entwicklung 2011, 20:111-118

16. Nock MK, Kessler RC: Prevalence of and risk factors for suicide attempts versus suicide gestures: analysis of the National Comorbidity Survey. J Abnorm Psychol 2006, 115:616-623.

17. Nitowski D, Petermann F: Nonsuicidal-self-injury: characteristics, assessment and risk factors. Psychother Psychosom Med Psychol 2011, 61:6-15.

18. Yates TM: The developmental psychopathology of self-injurious behavior: compensatory regulation in posttraumatic adaption. Clin Psychol Rev 2004, 24:35-74.

19. Deliberto TL, Nock MK: An exploratory study of correlates, onset, and offset of non-suicidal self-injury. Arch Suicide Res 2008, 12:219-231.

20. American Psychiatric Association: APA board of trustees approves DSM-V. News release No. 12-43, December 1st, 2012. www.dsm5.org.2012.

21. Regier DA, Narrow WE, Clarke DE, Kraemer HC, Kuramoto SJ, Kuhl EA, Kupfer DJ: DSM-5 Field Trial in the United States and Canada, Part II: Test-Retest Reliability of Selected Categorical Diagnoses. Am J Psychiatry 2013, 170(1):59-70.

22. American Psychiatric Association: Diagnostic and Statistical Manual of Mental Disorders, Fourth Edition, Text Revision. Washington, DC: American Psychiatric Association; 2000.

23. Nock MK, Joiner TE, Gordon EL, Prinstein MJ: Non-suicidal self-injury among adolescents: diagnostic correlates and relation to suicide attempts. Psychiatry Res 2006, 144:65-75.

24. Zlotnick C, Mattia Jl, Zimmerman M: Clinical correlates of self-mutilation in a sample of general psychiatric patients. J Nerv Ment Dis 1999, 187:296-301.

25. Herpertz S: Self-injurious behaviour: psychopathological and nosological characteristics in subtypes of self-injurers. Acta Psychiatr Scand 1995, 91:57-68.

26. Klonsky ED: Non-suicidal self-injury in United States adults: prevalence, sociodemographics, topography and functions. Psychol Med 2011, 41:1981-1986.

27. Muehlenkamp JJ, Gutierrez PM: Risk for suicide attempts among adolescents who engage in non-suicidal self-injury. Arch Suicide Res 2007, 11:69-82.

28. Favazza AR: The coming of age of self-mutilation. J Nerv Ment Dis 1998, 186:259-268.

29. Haines J, Williams $\mathrm{CL}$, Brain $\mathrm{KL}$, Wilson GV: The psychophysiology of selfmutilation. J Abnorm Psychol 1995, 104(3):471-489.

30. Klonsky ED: The function of self-injury in young adults who cut themselves: Clarifying the evidence for affect-regulation. Psychiatry Res 2009, 166(2-3):260-268.

31. Nixon MK, Cloutier PF, Aggarwal A: Affect regulation and addictive aspects of repetitive self-injury in hospitalized adolescents. J Am Acad Child Adolesc Psychiatry 2002, 41(11):1333-1341.

32. Gross Jj: The emerging field of emotion regulation: An integrative review. Rev Gen Psychol 1998, 2(3):271-299.

33. American Psychiatric Association: Diagnostic and Statistical Manual of Mental Disorders. 4th edition (DSM-IV). 4th edition. Washington: American Psychiatric Association; 1994.

34. Sloan DM, Kring AM: Emotion Regulation and Psychopathology. New York: Guilford Press; 2009.

35. Herpertz S: Neurobiologie der Borderline-Persönlichkeitsstörung. In Neurobiologie forensisch relevanter Störungen. Edited by Müller J. Stuttgart: Kohlhammer; 2009:341-351.

36. Znoj HJ, Herpertz SC, Mundt C: Affektregulation, Stressregulation. In Störungsorientierte Psychotherapie. Edited by Herpertz SC, Caspar F, Mundt C. Urban \& Schwarzenberg: (Elsevier); 2007:117-130. 
37. Gross JJ, Munoz RF: Emotion regulation and mental health. Clin Psychol Sci Pract 1995, 2:151-164.

38. Linehan MM: Cognitive-Behavioral Treatment of Borderline Personality Disorder. New York: Guilford Press; 1993.

39. Crowell S, Beauchaine TP, Linehan MM: A biosocial developmental model of borderline personality: elaborating and extending Linehan's theory. Psychol Bull 2009, 135:495-510.

40. Domes G, Schulze L, Herpertz SC: Emotion recognition in borderline personality disorder-a review of the literature. J Personal Disord 2009, 23:6-19.

41. Herpertz S, Dietrich TM, Wenning B, Krings T, Erberich SG, Willmes K, Thron A, Sass $\mathrm{H}$ : Evidence of abnormal amygdala functioning in borderline personality disorder: a functional MRI study. Biol Psychiatry 2001, 50:292-298.

42. Donegan NH, Sanislow CA, Blumberg HP, Fulbright RK, Lacadie C, Skudlarski P, Gore JC, Olson IR, McGlashan TH, Wexler BE: Amygdala hyperreactivity in borderline personality disorder: implications for emotional dysregulation. Biol Psychiatry 2003, 54:1284-1293.

43. Stiglmayr C, Grathwol T, Linehan M, Fahrenberg J, Bohus M: Aversive tension in patients with borderline personality disorder: a computerbased controlled field study. Acta Psychiatr Scand 2005, 111:379.

44. Linehan MM, Bohus M, Lynch T: Dialectical behavior therapy for pervasive emotion dysregulation. In Handbook of Emotion Regulation. Edited by Gross J. New York: Guilford Press; 2007:508-605.

45. Briere J, Gil E: Self-mutilation in clinical and general population samples: prevalence, correlates, and functions. Am J Orthopsychiatry 1998, 68:609-620.

46. Gratz KL: Risk factors for and function of deliberate self-harm: an empirical and conceptual review. Clin Psychol Sci Pract 2003, 10:192-205.

47. Thompson RA: Childhood anxiety disorders from the perspective of emotion regulation and attachment. In The Development of Anxiety. Edited by Vasey MW, Dadds MR. London: Oxford University Press; 2001:160-183.

48. Thompson RA: Emotion and self-regulation. In Nebraska Symposium on Motivation, 1988: Socioemotional development. Lincoln, NE: University of Nebraska Press; US; 1990:367-467.

49. Shaffer DR, Kipp K: Developmental Psychology: Childhood and Adolescence. 9th edition. Bellmont, USA: Wadsworth; 2012.

50. Fegert JM, Streeck-Fischer A, Freyberger HJ: Adoleszenzpsychiatrie. Psychiatrie und Psychotherapie der Adoleszenz und des jungen Erwachsenenalters. Stuttgart: Schattauer; 2009

51. Johnson JG, Cohen P, Chen H, Kasen S, Skodol AE, Hamagami F, Brook JS: Age-related change in personality disorder trait levels between early adolescence and adulthood: a community-based longitudinal investigation. Acta Psychiatr Scand 2000, 102:256-275.

52. Schmid M, Schmeck K, Petermann F: Persönlichkeitsstörungen im Kindesund Jugendalter? Kindheit Entwicklung 2008, 17:190-202.

53. Casey BJ, Jones RM, Levita L, Libby V, Pattwell S, Rubery E, Soliman F, Somerville LH: The storm and stress of adolescence: insights from human imaging and mouse genetics. Dev Psychobiol 2010, 52:225-235.

54. Fairchild G: The developmental psychopathology of motivation in adolescence. Dev Cogn Neurosci 2011, 1:414-429.

55. Hare TA, Tottenham N, Galvan A, Voss HU, Blover GH, Casey BJ: Biological substrates of emotional reactivity and regulation in adolescence during an emotional go-nogo task. Biol Psychiatry 2008, 63:927-934.

56. Powell K: Neurodevelopment: how does the teenage brain work? Nature 2006, 442:865-867

57. Giorgio A, Watkins KE, Chadwick M, James S, Winmill L, Douaud G, De Stefano N, Matthews PM, Smith SM, Johansen-Berg, James AC: Longitudinal changes in grey and white matter during adolescence. Neurolmage 2010, 49:94-103.

58. Brunner R, Henze R, Parzer P, Kramer J, Feigl N, Lutz K, Essig M, Resch F, Stieltjes $B$ : Reduced prefrontal and orbitofrontal gray matter in female adolescents with borderline personality disorder: is it disorder specific? Neurolmage 2010, 49:114-120.

59. Wahlstrom D, Collins P, White T, Luciana M: Developmental changes in dopamine neurotransmission in adolescence: behavioral implications and issues in assessment. Brain Cogn 2010, 72:146-159.

60. Vermeersch $H$, T'Sjoen $G$, Kaufman JM, Vincke J, Van Houtte M: Testosterone, androgen receptor gene CAG repeat length, mood and behaviour in adolescent males. Eur J Endocrinol 2010, 163:319-328.

61. Moran P, Coffey C, Romaniuk H, Olsson C, Borschmann R, Carlin JB, Patton GC: The natural history of self-harm from adolescence to young adulthood: a population-based cohort study. Lancet 2012, 379:236-243.
62. Hayes AM, Castonguay LG, Goldfried MR: Effectiveness of targeting the vulnerability factors of depression in cognitive therapy. J Consult Clin Psychol 1996, 64:623-627.

63. Jacobson CM, Gould M: The epidemiology and phenomenology of nonsuicidal self-injurious behavior among adolescents: a critical review of the literature. Arch Suicide Res 2007, 11:129-147.

64. Klonsky ED: The function of self-injury in young adults who cut themselves: clarifying the evidence for affect-regulation. Psychiatry Res 2009, 166:260-268.

65. Klonsky ED: The functions of deliberate self-injury: a review of the evidence. Clin Psychol Rev 2007, 27:226-239.

66. Suyemoto KL: The functions of self-mutilation. Clin Psychol Rev 1998, 18:531-554.

67. Nixon MK, Cloutier PF, Aggarwal S: Affect regulation and addictive aspects of repetitive self-injury in hospitalized adolescents. J Am Acad Child Adolesc Psychiatry 2002, 41:1333-1341.

68. Petermann F, Winkel S: Selbstverletztendes Verhalten. In Lehrbuch der Klinischen Kinderpsychologie. 6th edition. Edited by Petermann F. Göttingen: Hogrefe; 2008:461-476.

69. Brain KL, Haines J, Williams CL: The psychophysiology of self-mutilation: evidence of tension reduction. Arch Suicide Res 1998, 4:227-242.

70. Nock MK, Mendes WB: Physiological arousal, distress tolerance, and social problem-solving deficits among adolescent self-injurers. J Consul Clin Psychol 2008, 76:28-38.

71. In-Albon T, Schmid M: Selbstverletzendes Verhalten im Kindes- und Jugendalter. In Lehrbuch der Verhaltenstherapie. Band 4. Materialien für die Psychotherapie. Berlin: Springer; 2012:769-782.

72. Chapman AL, Gratz KL, Brown MZ: Solving the puzzle of deliberate selfharm: the experiential avoidance model. J Res Ther 2006, 44:371-394.

73. Nock MK: Why do people hurt themselves? New insights into the nature and function of self-injury. Curr Dir Psychol Sci 2009, 18:78-83.

74. Gross JJ: Emotion regulation: affective, cognitive, and social consequences. Psychophysiol 2002, 39:281-291.

75. Butler EA, Egloff B, Wilhelm FH, Smith NC, Erickson EA, Gross JJ: The social consequences of expressive suppression. Emotion 2003, 3:48-67.

76. Gross JJ, John OP: Wise emotion regulation. In The Wisdom of Feelings: Psychological Processes in Emotional Intelligence. Edited by Barrett LF, Salovey P. New York: Guilford Press; 2002:297-318.

77. Murata A, Moser JS, Kitayama S: Culture shapes electrocortical responses during emotion suppression. Soc Cogn Affect Neurosci 2012, 19. doi:10.1093/scan/nss036.

78. Suveg C, Zeman J: Emotion regulation in children with anxiety disorder. J Clin Child Adolesc Psychol 2004, 33:750-759.

79. Gross JJ: Handbook of Emotion Regulation. New York: Guilford; 2007.

80. Hatfield E, Cacioppo JL, Rapson RL: Emotional contagion. Curr Dir Psychol Sci 1994, 2:96-99.

81. Stepp SD, Pilkonis PA, Yaggi KE, Morse JQ, Feske U: Interpersonal and emotional experiences of social interactions in borderline personality disorder. J Nerv Ment Dis 2009, 197:484-491.

82. Ebner-Primer UW, Kuo J, Kleindienst N, Welch SS, Reisch T, Reinhard I, Lieb K, Linehan MM, Bohus M: State affective instability in borderline personality disorder assessed by ambulatory monitoring. Psychol Med 2007, 37:961-970.

83. Hilt LM, Cha CB, Nolen-Hoeksema S: Nonsuicidal self-injury in young adolescent girls: moderators of the distress-function relationship. $J$ Consult Clin Psychol 2008, 76:63-71.

84. Jovev M, Chanen A, Green M, Cotton S, Proffitt T, Coltheart M, Jackson H: Emotional sensitivity in youth with borderline personality pathology. Psychiatry Res 2011, 187:234-240.

85. Von Ceumern-Lindenstjerna IA, Brunner R, Parzer P, Frey M, Fiedler P, Resch F: Wahrnehmung und Bewertung von emotionalen Gesichtsausdrücken bei weiblichen Jugendlichen mit einer Borderline-Persönlichkeitsstörung. Z Kinder Jugendpsychiatr Psychother 2007, 35:333-340.

86. Hess $U$, Bourgeois P: You smile-I-smile: emotion expression in social interaction. Biol Psychol 2010, 84:514-520.

87. Darwin C: The expression of emotion in man and animals. London: Murray; 1872.

88. Ekman P: Universals and cultural differences in facial expressions of emotions. In Nebraska Symposium on Motivation. 19th edition. Edited by Coles JK. Lincoln: University of Nebraska Press; 1971:207-283. 
89. Dimberg U: Facial electromyography and emotional reactions. Psychophysiol 1990, 27:481-494.

90. Meltzoff AN, Moore MK: Imitation of facial and manual gestures by human neonates. Science 1977, 198:75-78.

91. Hall E: The Silent Language. New York: Doubleday; 1959

92. Hess U, Philippot P, Blairy S: Mimicry: facts and fiction. In The Social Context of Nonverbal Behavior. Studies in Emotion and Social Interaction. Edited by Philippot P, Feldman RS. Cambridge, UK: Cambridge University Press; 1999:213-241.

93. McIntosh D, Reichmann-Decker A, Winkielman P, Wilbargeret JL: When the social mirror breaks: deficits in automatic, but not voluntary, mimicry of emotional facial expressions in autism. Dev Sci 2006, 9:295-302.

94. Stel M, van den Heuvel C, Smeets RC: Facial feedback mechanisms in autistic spectrum disorders. J Autism Dev Disord 2008, 38:1250-1258.

95. Sloan DM, Bradley MM, Dimoulas E, Lang PJ: Looking at facial expressions: dysphoria and facial EMG. Biol Psychol 2002, 60:79-90.

96. Berking M, Wupperman P, Reichardt A, Pejic T, Dippel A, Znoj H: Emotionregulation skills as a treatment target in psychotherapy. Behav Res Ther 2008, 46:1230-1237.

97. Koerner K: Doing Dialectical Behavior Theory A Practical Guide. New York: Guilford; 2012.

98. Muehlenkamp JL: Empirically supported treatments and general therapy guidelines for non-suicidal self-injury. J Ment Health Counsel 2006, 28:166-185.

99. Klonsky ED, Muehlenkamp JJ: Self-injury: A research review for the practitioner. J Clin Psychol 2007, 63:1045-1056.

100. Fleischhaker C, Böhme R, Sixt B, Brück C, Schneider C, Schulz E: Dialectical behavioral therapy for adolescents (DBT-A): a clinical trial for patients with suicidal and self-injurious behavior and borderline symptoms with a one-year follow-up. Child Adolesc Psychiatry Ment Health 2011, 5(1):3.

101. Herpertz S: Wie beeinflussen neurobiologische Erkenntnisse die Psychotherapie? In Die Zukunft der Psychotherapie. Edited by Fiedler P. Heidelberg: Springer; 2012:41-66.

102. Berger T, Caspar F: Gewinnt die Psychotherapie durch die neurobiologische Erforschung der Wirkmechanismen? Zeitschrift für Psychiatrie, Psychologie und Psychotherapie 2011, 57:77-85.

103. Schnell K, Herpertz SC: Effects of dialectic-behavioral-therapy on the neural correlates of affective hyperarousal in borderline personality disorder. J Psychiatric Res 2007, 41:837-847.

104. Yehuda R, Bierer LM, Sarapas C, Martokinke I, Andrew R, SeckI JR: Cortisol metabolic predictors of response to psychotherapy for symptoms of PTSD in survivors of the World Trade Center attacks on September 11, 2001. Psychoneuroendocrinol 2009, 34:1304-1313.

105. Olff M, de Vries G-J, Güzelcan Y, Assiess J, Gersons BPR: Changes in Cortisol and DHEA plasma levels after psychotherapy for PTSD. Psychoneuroendocrinol 2007, 32:619-626.

106. Fruzzetti AE, Santisteban DA, Hoffman PD, Dimeff LA, Koerner K: Dialectical behavior therapy with families. In Dialectical Behavior Therapy in Clinical Practice. Applications across disorders and settings. New York: Guilford Press; 2007:222-244.

107. Schmid M, Libal G: Zur familientherapeutischen Arbeit mit Jugendlichen, die unter Borderlinepersönlichkeitsstörung leiden. Kontext $Z$ Familientherapie systemische Therapie 2010, 41:12-43.

108. Sato W, Kochiyama T, Yoshikawa S, Naito E, Matsumura M: Enhanced neural activity in response to dynamic facial expressions of emotion: an fMR study. Brian Res Cogn Brain Res 2004, 20:81-91.

109. Sato W, Fujimura T, Suzuki N: Enhanced facial EMG activity in response to dynamic facial expressions. Int J Psychophysiol 2008, 70:70-74.

110. Sato W, Yoshikawa S: Spontaneous facial mimicry in response to dynamic facial expressions. Cognition 2007, 104:1-18.

111. Bland AR, Williams CA, Scharer K, Manning S, Bland AR, Bland AR: Emotion processing in borderline personality disorders. Issues Ment Health Nurs 2004, 25:655-672.

doi:10.1186/1753-2000-7-5

Cite this article as: In-Albon et al: Non-suicidal self-injury and emotion regulation: a review on facial emotion recognition and facial mimicry. Child and Adolescent Psychiatry and Mental Health 2013 7:5. 